
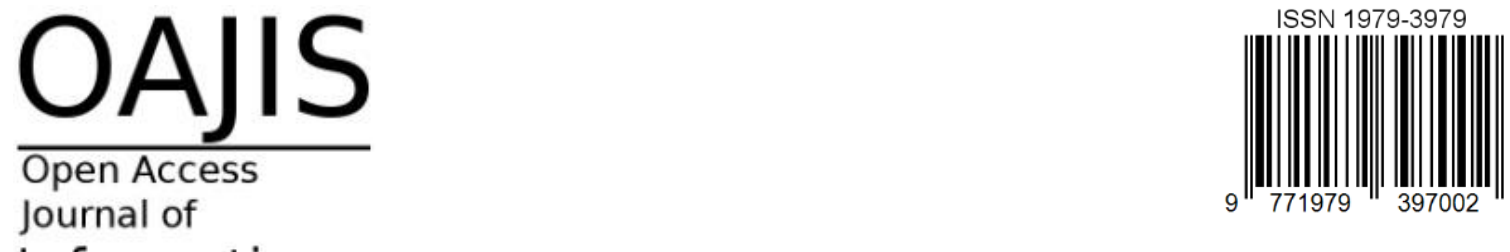

Information

Systems

is.its.ac.id/pubs/oajis/

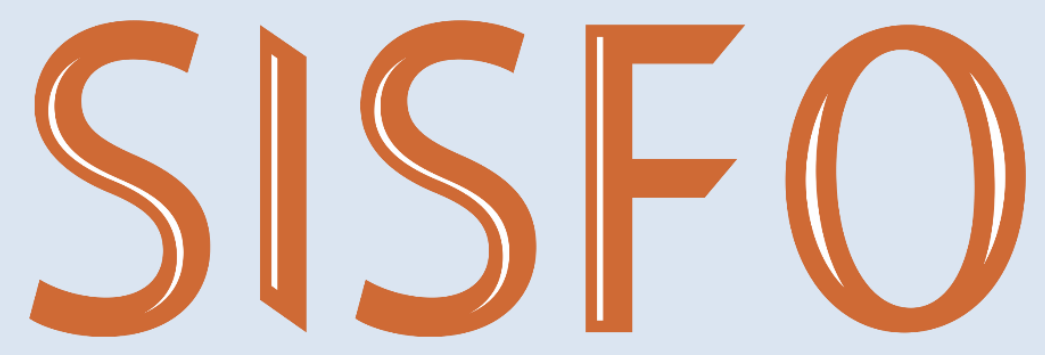

Inspirasi Profesional Sistem Informasi

\section{People}

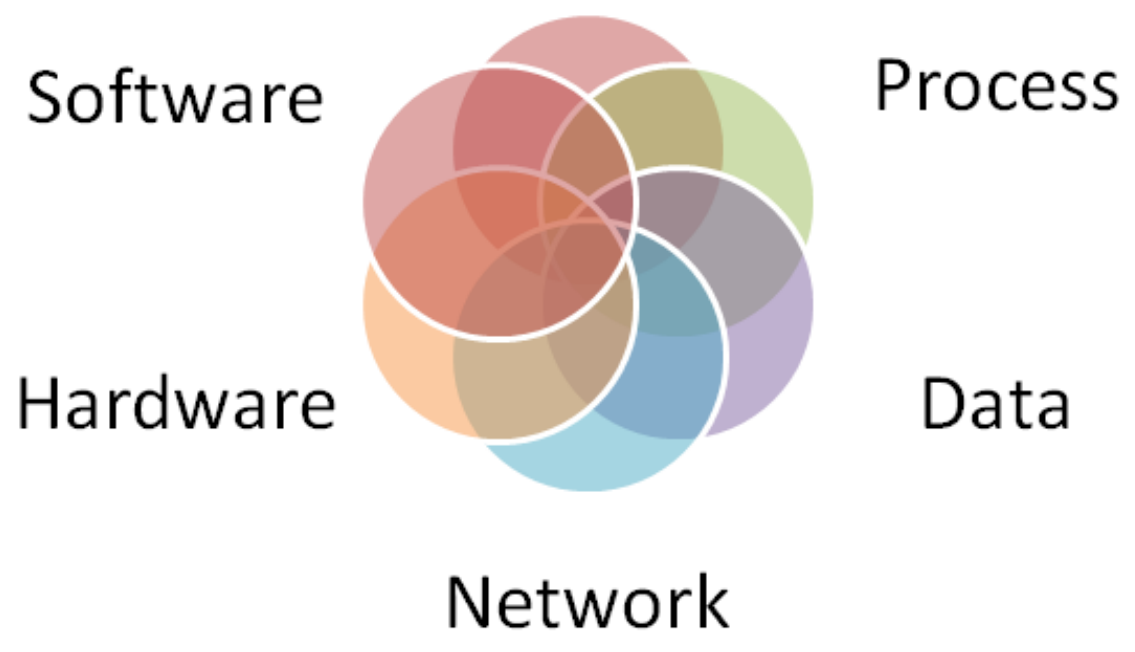


OAJIS

Journal of

Information

Systems

is.its.ac.id/pubs/oajis/

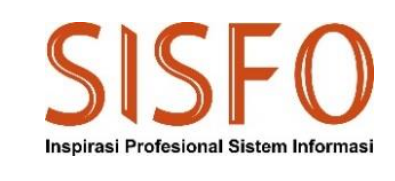

Jurnal Sisfo Vol. 09 No. 01 (2019) i-ii

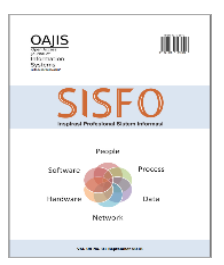

\section{Pimpinan Redaksi}

Faizal Mahananto

\section{Dewan Redaksi}

Eko Wahyu Tyas Darmaningrat

Amna Shifia Nisafani

Arif Wibisono

Rully Agus Hendrawan

\section{Tata Pelaksana Usaha}

Achmad Syaiful Susanto

Rini Ekowati

\section{Sekretariat}

Departemen Sistem Informasi - Fakultas Teknologi Informasi dan Komunikasi

Institut Teknologi Sepuluh Nopember (ITS) - Surabaya

Telp. 031-5999944 Fax. 031-5964965

Email: editor@jurnalsisfo.org

Website: http://jurnalsisfo.org

Jurnal SISFO juga dipublikasikan di Open Access Journal of Information Systems (OAJIS)

Website: http://is.its.ac.id/pubs/oajis/index.php 
OAJIS Journal of Information

Systems

is.its.ac.id/pubs/oajis/

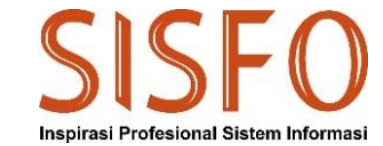

Jurnal Sisfo Vol. 09 No. 01 (2019) i-ii

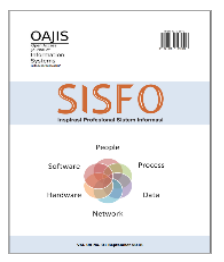

\section{Mitra Bestari}

A'ang Subiyakto, S.Kom., M.Kom., Ph.D. (UIN Syarif Hidayatullah Jakarta)

Alvin Sahroni, S.T., M.Eng., Ph.D. (Universitas Islam Indonesia)

Leon Andretti Abdillah, S.Kom., M.M. (Universitas Bina Darma)

Nur Aini Rakhmawati, S.Kom., M.Sc.Eng., Ph.D. (Institut Teknologi Sepuluh Nopember)

Renny Sari Dewi, S.Kom., M.Kom. (Universitas Internasional Semen Indonesia)

Reny Nadlifatin, S.Kom., M.BA., Ph.D. (Institut Teknologi Sepuluh Nopember)

Retno Aulia Vinarti, S.Kom., M.Kom., Ph.D. (Institut Teknologi Sepuluh Nopember)

Rradityo Prasetianto Wibowo, S.Kom., M.Kom. (Institut Teknologi Sepuluh Nopember)

Satria Fadil Persada, S.Kom., M.BA., Ph.D. (Institut Teknologi Sepuluh Nopember)

Sholiq, S.T., M.Kom. (Institut Teknologi Sepuluh Nopember)

Yogantara Setya Dharmawan, S.Kom., MBusProcessMgt (Universitas Internasional Semen Indonesia) 


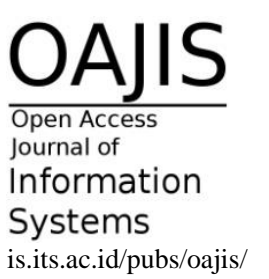

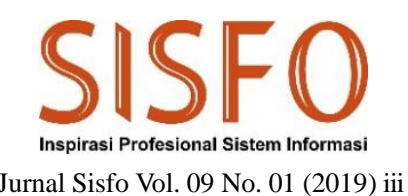

Jurnal Sisfo Vol. 09 No. 01 (2019) iii

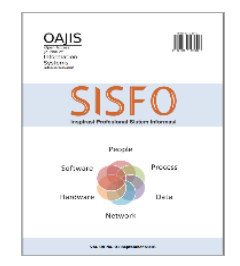

\section{Daftar Isi}

Perencanaan Strategi SI/TI Menggunakan Metode Ward and Peppard di BARENLITBANGDA Kabupaten Semarang

Dedy, Prihanto Ngesti Basuki, Hanna Prillysca Chernovita

Penggunaan Algoritma C4.5 untuk Rekomendasi Peminjaman Uang pada Koperasi Sejahtera Mandiri

Muhammad Imam Tegar, Wachyu Hari Haji.....

Analysis of Purchase Intention using Mobile Shopping Application for Generation X and Y in Indonesia

Mudjahidin, Andre Parvian Aristio, Al Lilah Nur Hasanah.

Analisis Struktur Service Desk di Perguruan Tinggi (Studi Kasus: Institut Teknologi Sepuluh Nopember Surabaya)

Anisah Herdiyanti, Mona Syahmi, Tony Dwi Susanto

Analisis Intensi Perilaku Untuk Mengadopsi dan Merekomendasikan Aplikasi Mobile Payment dengan Metode Structural Equation Modelling

Andre Parvian Aristio, Mudjahidin, Nasywa Ibtisamah. 51 
Halaman ini sengaja dikosongkan 


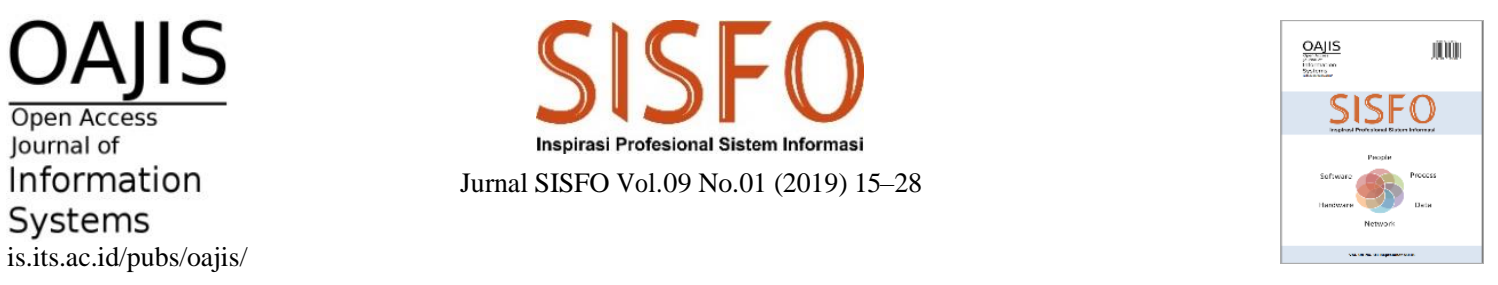

\title{
Penggunaan Algoritma C4.5 untuk Rekomendasi Peminjaman Uang pada Koperasi Sejahtera Mandiri
}

\author{
Muhammad Imam Tegar*, Wachyu Hari Haji \\ Program Studi Informasi, Fakultas Ilmu Komputer, Universitas Mercu Buana
}

\begin{abstract}
Koperasi Sejahtera Mandiri provides money lending services to its members based on the main criteria for lending limits. This money lending service has constraints such as the many requests of members who want to borrow money, causing cash in the cooperative is not sufficient to provide loans. This study aims to select members who want to borrow categorized based on lending limits to be given recommendations for lending. The data collection techniques and methods used were interviews with the chairman of the cooperative to get the dataset. The next process is to classify using the dataset obtained and group data by borrower category and type of loan using C4.5 Algorithm. From the calculation process using the $\mathrm{C} 4.5$ Algorithm, it is obtained which member recommendations should be given loans and which should not, so that money lending transactions do not cause losses for cooperatives.
\end{abstract}

Keywords: Member, Borrow Money, Sejahtera Mandiri Cooperative, C4.5 Algorithm

\begin{abstract}
Abstrak
Koperasi Sejahtera Mandiri menyediakan jasa layanan peminjaman uang kepada anggotanya berdasarkan kriteria utama limit peminjaman. Layanan peminjaman uang ini memiliki kendala seperti banyaknya permintaan anggota yang ingin meminjam uang sehingga menyebabkan kas pada koperasi tidak mencukupi untuk memberikan pinjaman. Penelitian ini bertujuan untuk menyeleksi anggota yang ingin meminjam dengan dikategorikan berdasarkan limit peminjaman untuk diberikan rekomendasi pemberian peminjaman. Adapun teknik pengumpulan data dan metode yang digunakan adalah wawancara dengan ketua koperasi untuk mendapatkan dataset. Proses selanjutnya adalah melakukan klasifikasi menggunakan dataset yang diperoleh serta mengelompokkan data berdasarkan kategori peminjam dan jenis peminjaman menggunakan Algoritma C4.5. Dari proses perhitungan dengan Algoritma C4.5 diperoleh rekomendasi anggota mana yang sebaiknya diberikan pinjaman dan yang tidak, sehingga transaksi peminjaman uang tidak menimbulkan kerugian bagi koperasi.
\end{abstract}

Kata kunci: Anggota, Peminjaman Uang, Koperasi Sejahtera Mandiri, Algoritma C4.5

(C) 2019 Jurnal SISFO.

Histori Artikel: Disubmit 26-08-2019; Direvisi 23-09-2018; Diterima 29-09-2019; Tersedia online 30-09-2019

${ }^{*}$ Corresponding Author
Email address: 41815010036@ student.mercubuana.ac.id (Muhammad Imam Tegar)
https://doi.org/10.24089/j.sisfo.2019.09.002 


\section{Pendahuluan}

Pada era saat ini perkembangan bisnis semakin kompetitif. Setiap koperasi bersaing untuk melayani anggota dengan baik, dan memberi layanan yang bisa memenuhi kebutuhan anggotanya terutama dalam peminjaman uang. Uang sekarang dibutuhkan sebagai alat transaksi jual beli untuk memenuhi kebutuhan primer dan sekunder, maka dari itu pihak koperasi menyediakan layanan peminjaman uang untuk membantu memenuhi kebutuhan primer terutama pada anggotanya. Koperasi Sejahtera Mandiri melakukan transaksi peminjaman uang kepada anggota dari persedian kas untuk peminjaman, akan tetapi Koperasi Sejahtera Mandiri mempunyai kas yang sangat terbatas. Oleh karena itu, penelitian ini menggunakan algoritma C4.5 untuk membuat suatu keputusan dan memberikan rekomendasi kepada koperasi untuk menentukan anggota yang akan diberi pinjaman.

Kondisi Koperasi Sejahtera Mandiri saat ini sudah mengalami peralihan sistem. Sebelumnya koperasi belum mempunyai sistem terstruktur, namun sekarang koperasi sudah mulai menerapkan sistem informasi. Banyak koperasi di Indonesia yang tidak memberi pinjaman uang secara langsung, akan tetapi mereka menerapkan kriteria dalam peminjaman uang untuk menghindari kerugian terhadap koperasi, misalnya kerugian karena tidak kembalinya uang yang dipinjamkan pada waktu yang ditentukan dan keterlambatan dalam melakukan pengembalian. Adapun faktor penyebab keterlambatan pengembalian atau tidak kembalinya pemberian peminjaman antara lain disebabkan oleh faktor anggota itu sendiri yang pada saat peminjaman masih mengalami kekurangan uang untuk memenuhi kebutuhan primernya contoh biaya sekolah anak, dan terkadang ada biaya yang tak diduga misalnya biaya rawat inap di rumah sakit. Berdasarkan permasalahanpermasalahan tersebut, penulis mempunyai tujuan untuk menggunakan metode klasifikasi pada algoritma C4.5 guna menyelesaikan masalah yang dialami oleh koperasi.

Dengan menggunakan algoritma C4.5 untuk mengidentifikasi masalah dalam peminjaman uang, dapat menghindari risiko tidak kembalinya uang yang dipinjamkan [1]. Adapun metode yang digunakan untuk permasalahan ini yaitu metode klasifikasi dengan menempatkan objek-objek kedalam salah satu kategori yang ditetapkan oleh peneliti sebelumnya [2]. Hasil luaran dari proses Data Mining dengan menggunakan algoritma $\mathrm{C} 4.5$ yang berupa rekomendasi pemberian peminjaman uang terhadap anggota ini dapat digunakan untuk pengambilan keputusan untuk dipertimbangkan kembali siapa yang layak untuk menerima pinjaman [3]. Hal ini berarti peminjaman uang bisa diberikan berdasarkan keputusan dari atasan atau manager bagian keuangan [4].

Data mining membuat proses untuk menemukan pola tersembunyi dalam data menjadi lebih mudah. Proses ini dapat memberikan keuntungan khususnya bagi kebutuhan ekonomi pada koperasi yang memiliki data dalam jumlah yang besar [5]. Hasil luaran data mining dapat digunakan untuk pengambilan keputusan pada koperasi dalam melakukan kegiatan operasionalnya [6]. Data mining biasanya didukung oleh algoritma dalam penyelesaian masalah untuk relasi data [7]. Selain itu data mining dikenal dengan Knowledge Discovery in Database yang berarti kegiatan pengumpulan data untuk menemukan pola dalam dataset yang berukuran besar [8].

Algoritma C4.5 menggunakan metode klasifikasi dengan menempatkan suatu kelompok atau kategori yang ditentukan, kemudian memberikan rekomendasi berdasarkan dataset yang disediakan [2]. Selain itu klasifikasi bisa memprediksi data yang mempunyai nilai kategorikal [9]. Setelah metode klasifikasi digunakan pada algoritma C4.5, kemudian akan dilakukan pembentukan pohon keputusan berdasarkan hasil dari klasifikasi dengan perhitungan algoritma C4.5 [10]. Pada tahap pembuatan pohon keputusan berdasarkan proses pengujian data dapat dibuat model pohon keputusan yang mempunyai nilai akurat [11]. Hal ini bertujuan untuk membantu kegiatan simpan pinjam dan dalam mengelola data untuk mendapatkan informasi yang dapat dijadikan sebagai dasar pengambilan keputusan yang akan dilakukan oleh pimpinan [12]. 
Dari hasil penelitian ini, penulis berharap dapat memberikan solusi untuk meningkatkan pengelolaan pinjaman pada Koperasi Sejahtera Mandiri dan membantu pimpinan dalam mengambil keputusan dengan mempertimbangkan rekomendasi yang dihasilkan oleh algoritma C4.5. Rekomendasi ini diharapkan dapat memilih anggota yang layak menerima pinjaman sehingga dapat menghindari kerugian keuangan yang disebabkan oleh pinjaman uang yang tidak dikembalikan.

\section{Tinjauan Pustaka/Penelitian Sebelumnya}

Algoritma C4.5 sudah banyak digunakan oleh peneliti untuk menyelesaikan permasalahan di berbagai bidang. Penelitian oleh Elisa [1] menyelesaikan permasalahan penyebab kecelakaan kerja konstruksi menggunakan algoritma C4.5 untuk mengidentifikasi faktor penyebab kecelakaan dengan penggunaan metode klasifikasi. Data yang digunakan dalam penelitian ini antara lain meliputi cara kerja dan bagaimana pekerja melakukan pekerjaan, lingkungan tempat pekerja, rambu keselamatan, dan alat pelindung diri. Datadata ini kemudian dikelompokkan untuk mencari kemungkinan penyebab kecelakaan berdasarkan peluang sering terjadi sampai jarang terjadi. Kemudian penelitian Yasmiati et al. [10] memprediksi perilaku mahasiswa di masa depan dengan menggunakan algoritma C4.5 untuk memperoleh informasi mengenai pengetahuan, motivasi, metakognisi, dan sikap. Sedangkan penelitian oleh Kamagi dan Seng [14] membahas tentang prediksi tingkat kelulusan mahasiswa berdasarkan 4 kategori, antara lain lulus cepat, lulus tepat waktu, lulus terlambat, dan drop out dengan hasil yang dihitung menggunakan algoritma C4.5. Penelitian oleh Br Ginting et al. [15] memprediksi masa studi mahasiwa dengan menggunakan algoritma C4.5. selain itu, penelitian oleh Rohman et al. [16] memecahkan masalah dengan menggunakan algorima C4.5 untuk menentukan akurasi pasien yang berpotensi terkena penyakit jantung.

Lebih lanjut, Harryanto dan Hansun [17] menyelesaikan masalah pada perusahaan berdasarkan potensi dengan menggunakan algoritma C4.5 dengan mengelompokan keterampilan setiap karyawan maupun calon karyawannya. Penelitian oleh Widayu et al. [18] menyelesaikan masalah pada identifikasi jenis transaksi nasabah untuk pengambilan keputusan yang mana pihak manajer akan menawarkan suatu jasa kepada nasabah untuk menarik minat dan perhatiannya berdasarkan perhitungan algoritma C4.5. Penelitian oleh Rahmayuni [19] menyelesaikan masalah hasil yang lebih baik pada nilai mahasiswa dengan menggunakan algoritma C4.5. Penelitian oleh Meilina [2] menyelesaikan permasalahan tentang pengiriman gas yang diprioritaskan berdasarkan skala prioritas pada tiap-tiap kelurahan dengan menggunakan decision tree berdasarkan hasil regresi per kelurahan. Untuk studi ini berkaitan dengan penggunaan decision tree berdasarkan skala prioritas berdasarkan kebutuhan peminjaman dan limit peminjaman. Pada penelitian kali ini penulis menggunakan metode yang serupa yaitu klasifikasi yang berujuan untuk mengelompokan prioritas anggota untuk melakukan peminjaman uang yang diajukan kepada koperasi.

\subsection{Data Mining}

Perolehan suatu informasi berawal dari penggalian data yang mempunyai skala besar dan bermanfaat [13]. Data Mining bisa menangani jumlah data yang sangat besar dan juga dapat menampung volume data yang sangat tinggi [14]. Data Mining terbagi dalam dua metode yaitu metode prediktif yang merupakan suatu proses penemuan data berdasarkan pola dengan menggunakan variabel yang belum teridentifikasi nilai ataupun jenisnya, serta metode deskriptif yang merupakan suatu proses untuk menemukan karakteristik utama dalam suatu basis data [15].

\subsection{Decision Tree}

Pohon keputusan mempunyai kelebihan dalam mengolah dataset diantaranya mempunyai pengklasifikasian yang baik, tiap atribut bersifat diskrit, menggunakan bilangan biner, dan transparansi akan pengetahuan klasifikasi [16]. Adapun kekurangan dari pohon keputusan adalah terjadinya overlap pada hasil keputusan dan kriteria pengambilan keputusan yang sangat banyak mengakibatkan bertambahnya waktu dari hasil 
prediksi sebelumnya [17]. Gambar 1 berikut menjelaskan cara atau tahapan bagaimana algoritma decision tree $(\mathrm{C} 4.5)$ bekerja.

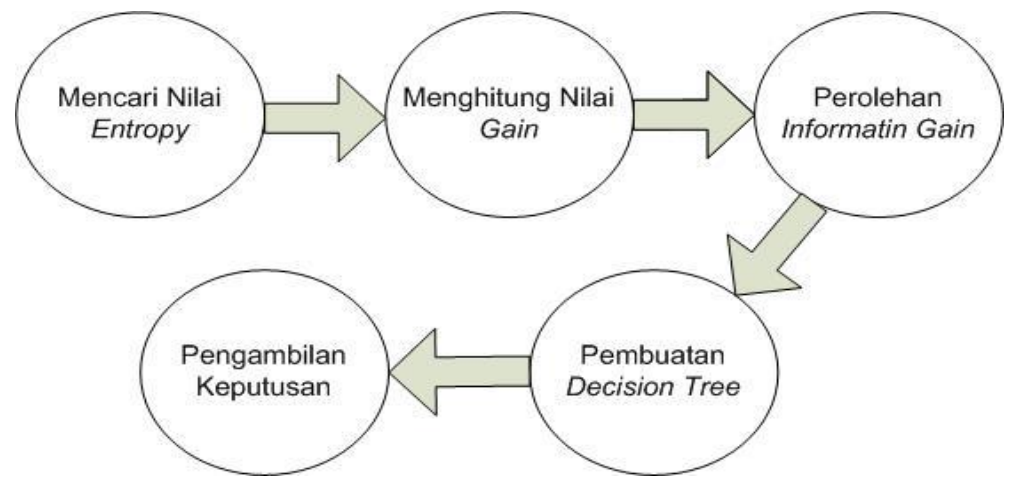

Gambar 1. Tahapan algoritma C4.5 terhadap information gain

Gambar 1 menunjukkan bahwa algoritma decision tree terutama C4.5 mempunyai langkah-langkah yang dapat menarik suatu keputusan berdasarkan hasil dari proses data mining. Langkah pertama dimulai dari mencari nilai entropy terlebih dahulu untuk dijadikan acuan untuk perhitungan entropy selanjutnya. Kemudian setelah mendapatkan nilai entropy, maka nilai gain akan dihitung untuk memperoleh nilai yang mempunyai potensi sebagai informasi yang penting. Setelah itu didapatkan information gain sebagai pendapatan informasi untuk dijadikan tolak ukur pada pembuatan pohon keputusan. Dengan dibuatnya pohon keputusan yang menggunakan information gain sebagai poin utamanya, maka dapat ditarik kesimpulan yang berupa keputusan pada langkah perolehan informasi.

\subsection{Algoritma C4.5}

Algoritma C4.5 merupakan algoritma yang digunakan untuk membangun sebuah pohon keputusan (decision tree) dari data. Algoritma C4.5 merupakan pengembangan dari algoritma ID3 yang juga merupakan algoritma untuk membangun sebuah pohon keputusan. Algoritma C4.5 secara rekursif mengunjungi tiap simpul keputusan, memilih percabangan optimal, sampai tidak ada cabang lagi yang mungkin dihasilkan [18]. Tujuan dari algoritma C4.5 adalah membangun struktur data pohon yang akan digunakan untuk memprediksi kelas dari sebuah kasus atau record yang belum memiliki kelas [19]. Adapun tahapan-tahapan untuk melakukan perhitung algoritma C4.5 diantaranya, menyiapkan data training, menentukan akar dari pohon dengan menghitung entropy, kemudian menghitung nilai gain, setelah itu menentukan tupel yang ingin dipartisi [1].

\section{Metodologi}

Pada penelitian ini teknik pengumpulan data yang digunakan antara lain yaitu metode observasi dengan melakukan pengamatan secara langsung dan mengamati Koperasi Sejahtera Mandiri serta kemudian mengidentifikasi masalah yang ada pada Koperasi Sejahtera Mandiri dengan melihat kondisi sistem peminjaman uang yang berjalan. Wawancara dilakukan dengan dialog atau mengajukan pertanyaan kepada ketua koperasi mengenai segala sesuatu yang berhubungan dengan masalah yang diteliti. Tahapan ini dilakukan dengan cara tanya jawab. Dengan menganalisa hasil pertanyaan dan jawaban tersebut maka dapat diketahui masalah yang terjadi pada Koperasi Sejahtera Mandiri. 


\subsection{Identifikasi Masalah}

Identifikasi masalah dilakukan untuk menemukan masalah apa saja yang ada pada objek penelitian yaitu Koperasi Sejahtera Mandiri berupa latar belakang apa yang mendasari masalah tersebut harus diteliti dengan intensif. Adapun masalah yang terdapat pada Koperasi Sejahtera Mandiri yaitu koperasi kesulitan memberikan pinjaman berdasarkan ketersediaan uang kas yang dimiliki dan banyaknya jumlah peminjam, sehingga perlu menentukan skala prioritasnya. Kemudian dilakukan analisa masalah untuk lebih menguraikan secara rinci persoalan yang belum terselesaikan pada objek penelitian. Adapun tujuan penelitian ini adalah untuk memberikan solusi tentang permasalahan yang terjadi pada objek penelitian dengan upaya meminimalisir permasalahan tersebut jika tidak bisa diselesaikan secara tuntas.

\subsection{Dataset dan Perhitungan Algoritma}

Dari hasil wawancara didapatkan dataset yang diperlukan untuk menyelesaikan permasalahan yang ada pada Koperasi Sejahtera Mandiri, dataset yang diberikan seperti pada Tabel 1 berikut.

Table 1. Tabel dataset peminjaman

\begin{tabular}{cll}
\hline \multicolumn{2}{c}{ Table 1. Tabel dataset peminjaman } \\
\hline No & \multicolumn{1}{c}{ Nama Anggota } & \multicolumn{1}{c}{ Jumlah Pinjaman } \\
\hline 1 & Andi & Rp. 685.000,- \\
2 & Rian & Rp. 1.000.000,- \\
3 & Putri & Rp. 490.000,- \\
4 & Rina & Rp. 354.500,- \\
5 & Budi & Rp. 172.500,- \\
6 & Dani & Rp. 558.000,- \\
7 & Andika & Rp. 1.389.000,- \\
8 & Sinta & Rp. $981.000,-$ \\
9 & Randy & Rp. 467.300,- \\
10 & Bani & Rp. 201.100,- \\
\hline
\end{tabular}

Adapun perhitungan algoritma C4.5 untuk melakukan proses data mining berdasarkan dataset yang ada dilakukan dengan cara dan rumus sebagai berikut.

\section{1) Mencari Nilai Entropy}

Tahapan pertama dalam algoritma $\mathrm{C} 4.5$ adalah mencari nilai entropynya terlebih dahulu. Tujuannya sebagai parameter penentu awal dalam perhitungan algoritma $\mathrm{C} 4.5$ dengan rumus seperti pada Persamaan (1) berikut.

$$
\operatorname{Entropy}(S)=\sum_{i=1}^{n}-p i \cdot \log _{2} p i
$$

\section{2) Menghitung Nilai Gain}

Perhitungan nilai gain dari perolehan hasil nilai entropy betujuan untuk menentukan hasil akhir yang berupa information gain atau perolehan informasi yang penting untuk membuat suatu keputusan, dengan rumus perhitungan seperti pada Persamaan (2) berikut.

$$
\operatorname{Gain}(S, A)=\operatorname{Entropy}(S)-\sum_{v \in \operatorname{Values}(A)} \frac{\left|S_{v}\right|}{|S|} \operatorname{Entropy}\left(S_{v}\right)
$$


Setelah didapatkan semua hasil dari perhitungan entropy dan gain berdasarkan dataset, maka didapatkan hasil berupa suatu pohon keputusan dan penentuan klasifikasinya dengan akar sebagai pengelompokannya. Berdasarkan informasi pada pohon keputusan itulah dapat ditentukan siapa saja anggota koperasi yang layak diberikan peminjaman atau tidak.

\subsection{Pemberi Layanan Peminjaman Uang}

Jika sudah melewati perhitungan algoritma dan mendapatkan hasil yang sesuai maka akan diberikan rekomendasi peminjaman uang dengan limit peminjaman yang masih baik dan bagian manajemen keuangan akan memberikan uangnya kepada orang yang direkomendasikan.

\subsection{Membuat Laporan Hasil Rekomendasi Peminjaman}

Dengan hasil direkomendasikan atau tidaknya seorang anggota untuk diberikan peminjaman maka akan dibuat laporan untuk menngetahui anggota mana saja yang berhak dan yang tidak berhak menerima pinjaman berdasarkan limit yang ditetapkan bagi anggota Koperasi Sejahtera Mandiri.

\section{Hasil dan Pembahasan}

Anggota koperasi merupakan karyawan dari PT. Parkland World Indonesia yang mempunyai masalah pada pemberian gaji karyawan karena belum memenuhi standar kebutuhan pokok karyawan. Hal ini dikarenakan kedudukan atau jabatan karyawan tersebut masih dalam posisi yang relative rendah sehingga mempunyai gaji dibawah standar.

Koperasi Sejahtera Mandiri terutama bagian keuangan yang menyangkut jasa pelayanan peminjaman uang mempunyai permasalahan yang disebabkan oleh banyaknya anggota yang belum mengembalikan pinjaman uang yang diberikan oleh pihak koperasi. Selain itu koperasi juga memiliki masalah dalam menentukan siapa saja anggota yang layak diberikan peminjaman, karena Koperasi Sejahtera Mandiri masih belum mempunyai suatu perencanaan atau belum memiliki dasar pengambilan keputusan yang tepat untuk memberikan peminjaman terhadap anggotanya.

Adapun hasil analisis SWOT untuk Koperasi Sejahtera Mandiri yang dilakukan pada penelitian ini adalah sebagai berikut.

\section{1) Strength (Kekuatan)}

Koperasi Sejahtera Mandiri mempunyai layanan peminjaman uang untuk kebutuhan primer yang bisa dirasakan manfaatnya oleh anggota dan keluarganya. Setiap anggota yang memiliki pinjaman akan dipotong gajinya untuk cicilan pengembalian.

\section{2) Weakness (Kelemahan)}

Adanya kekurangan yang dimiliki pada penerapan peminjaman yang berjalan, diantaranya kurang memperhitungkan persediaan uang yang dimiliki oleh koperasi sehingga peminjaman diberikan setiap minggunya tanpa adanya batasan peminjaman.

\section{3) Opportunity (Peluang)}

Koperasi Sejahtera Mandiri mempunyai peluang sebagai koperasi digital, misalnya layanan peminjaman uang dan riwayat peminjaman uang dapat dirancang menggunakan sebuah sistem berbasis elektronik. Selain itu, bisa dijadikan motivasi bagi koperasi lainnya yang masih menggunakan sistem pencatatan dan perhitungan berbasis arsip. 


\section{4) Threat (Ancaman)}

Adapun ancaman yang akan didapat dari layanan peminjaman uang yaitu risiko kerugian kas yang disebabkan tidak adanya pengembalian uang dari anggota setelah pemberian pinjaman uang.

Berdasarkan hasil analisa tersebut, peneliti mendapatkan sampel data dari Koperasi Sejahtera Mandiri berupa data Peminjaman Uang perharinya yaitu berjumlah 10 record yang akan dihitung dan dibuat pohon keputusannya menggunakan Algoritma C4.5. Hasil dari proses klasifikasi yang berupa aturan-aturan dapat digunakan untuk memprediksi nilai atribut bertipe diskrit dari record yang baru [1]. Adapun sampel data dan hasil parameter yang ditentukan untuk penyelesaian masalah adalah seperti yang ditampilkan pada Tabel 2 berikut.

Tabel 2. Dataset peminjaman uang

\begin{tabular}{lllll}
\hline \multirow{2}{*}{ No } & Nama Anggota & Limit Pinjaman & Jumlah Pinjaman & Jenis Pinjaman \\
\hline 1 & Andi & High & Rp. 685.000,- & Reguler \\
2 & Rian & Medium & Rp. 1.000.000,- & Taktis \\
3 & Putri & Medium & Rp. 490.000,- & Darurat \\
4 & Rina & Low & Rp. 354.500,- & Reguler \\
5 & Budi & High & Rp. 172.500,- & Taktis \\
6 & Dani & High & Rp. 558.000,- & Reguler \\
7 & Andika & Low & Rp. 1.389.000,- & Darurat \\
8 & Sinta & Medium & Rp. 981.000,- & Taktis \\
9 & Randy & High & Rp. 467.300,- & Reguler \\
10 & Bani & Low & Rp. 201.100,- & Darurat \\
\hline
\end{tabular}

"Limit Peminjaman" pada Koperasi Sejahtera Mandiri yaitu, Low = mempunyai batasan peminjaman dengan nominal 0,- - 350.000,- dan riwayat peminjaman yang kurang baik; Medium = mempunyai batasan peminjaman dengan nominal 350.001,- - 1.000.000,- dan riwayat peminjaman lumayan baik; High = mempunyai batasan peminjaman dengan nominal $\geq 1.000 .001$,- dan riwayat peminjaman sangat baik.

Adapun "Jenis Pinjaman" pada setiap peminjaman dengan sifat dasarnya diantara lain yaitu, Reguler = anggota bisa melakukan peminjaman dengan nominal minimal 100.000,- - 1.000.000,-; Taktis $=$ anggota yang melakukan peminjaman bersifat ini bisa melakukan peminjaman dengan skala bertumpuk; dan Darurat = anggota meminjam untuk keperluan yang bersifat harus cepat diberi pinjaman misalnya untuk biaya rumah sakit atau berobat.

Adapun sampel contoh perhitungan yang diambil sebagian untuk mencari nilai entropy dan nilai gain adalah sebagai berikut.

1) Menghitung nilai entropy. Dari data peminjaman uang diketahui jumlah anggota yang meminjam ada 10, yang mempunyai limit pinjaman high 4 record, medium 3 record, dan low 3 record sehingga di dapat entropy nilai akar totalnya berdasarkan rumus pada Persamaan (1) sebagai berikut.

$$
\operatorname{Entropy}(S)=\sum_{i=1}^{n}-p i . \log _{2} p i
$$




$$
\begin{aligned}
& =\left(-\frac{4}{10} \cdot \log _{2}\left(\frac{4}{10}\right)\right)+\left(-\frac{3}{10} \cdot \log _{2}\left(\frac{3}{10}\right)\right)+\left(-\frac{3}{10} \cdot \log _{2}\left(\frac{3}{10}\right)\right) \\
& =\left(-0.4 \cdot\left(\frac{-0.39794}{\log _{2}}\right)\right)+\left(-0.3 \cdot\left(\frac{-0.52288}{\log _{2}}\right)\right)+\left(-0.3 \cdot\left(\frac{-0.52288}{\log _{2}}\right)\right) \\
& =\left(-0.4 \cdot\left(\frac{-0.39794}{0.30103}\right)\right)+\left(-0.3 \cdot\left(\frac{-0.52288}{0.30103}\right)\right)+\left(-0.3 \cdot\left(\frac{-0.52288}{0.30103}\right)\right) \\
& =(-0.4 \cdot-1.32193)+(-0.3 \cdot-1.73697)+(-0.3 \cdot-1.73697) \\
& =0.2115+0.5211+0.5211 \\
& =1.2537
\end{aligned}
$$

2) Menghitung nilai entropy dari data limit peminjaman Low yang diketahui jumlah kasus ada 3, yang jenis peminajamannya bersifat reguler ada 1 record, bersifat taktis ada 1 record, dan yang bersifat darurat ada 1 record sehingga di dapat nilai Lownya sebagai berikut.

$$
\begin{gathered}
\text { Entropy }(S)=\sum_{i=1}^{n}-p i \cdot \log _{2} p i \\
=\left(-\frac{1}{3} \cdot \log _{2}\left(\frac{1}{3}\right)\right)+\left(-\frac{1}{3} \cdot \log _{2}\left(\frac{1}{3}\right)\right)+\left(-\frac{1}{3} \cdot \log _{2}\left(\frac{1}{3}\right)\right) \\
=\left(-0.3333 \cdot\left(\frac{-0.47712}{\log _{2}}\right)\right)+\left(-0.3333 \cdot\left(\frac{-0.47712}{\log _{2}}\right)\right)+\left(-0.3333 \cdot\left(\frac{-0.47712}{\log _{2}}\right)\right) \\
=\left(-0.3333 \cdot\left(\frac{-0.47712}{0.30103}\right)\right)+\left(-0.3333 \cdot\left(\frac{-0.47712}{0.30103}\right)\right) \\
\quad+\left(-0.3333 \cdot\left(\frac{-0.47712}{0.30103}\right)\right) \\
=(-0.3333 \cdot-1.5849)+(-0.3333 \cdot-1.5849)+(-0.3333 \cdot-1.5849) \\
=0.5282+0.5282+0.5282 \\
=1.5846 \quad
\end{gathered}
$$

3) Menghitung nilai entropy dari data limit peminjaman Medium yang diketahui jumlah kasus ada 3, yang jenis peminjamannya bersifat reguler ada 1 record, bersifat taktis ada 1 record, dan yang bersifat darurat ada 1 record sehingga di dapat nilai Mediumnya sebagai berikut.

$$
\operatorname{Entropy}(S)=\sum_{i=1}^{n}-p i . \log _{2} p i
$$




$$
\begin{aligned}
& =\left(-\frac{1}{3} \cdot \log _{2}\left(\frac{1}{3}\right)\right)+\left(-\frac{1}{3} \cdot \log _{2}\left(\frac{1}{3}\right)\right)+\left(-\frac{1}{3} \cdot \log _{2}\left(\frac{1}{3}\right)\right) \\
& =\left(-0.3333 \cdot\left(\frac{-0.47712}{\log _{2}}\right)\right)+\left(-0.3333 \cdot\left(\frac{-0.47712}{\log _{2}}\right)\right)+\left(-0.3333 \cdot\left(\frac{-0.47712}{\log _{2}}\right)\right) \\
& =\left(-0.3333 \cdot\left(\frac{-0.47712}{0.30103}\right)\right)+\left(-0.3333 \cdot\left(\frac{-0.47712}{0.30103}\right)\right)+\left(-0.3333 \cdot\left(\frac{-0.47712}{0.30103}\right)\right) \\
& =(-0.3333 \cdot-1.5849)+(-0.3333 \cdot-1.5849)+(-0.3333 \cdot-1.5849) \\
& =0.5282+0.5282+0.5282 \\
& =1.5846
\end{aligned}
$$

4) Menghitung nilai entropy dari data limit peminjaman High yang diketahui jumlah kasus ada 4, yang jenis peminajamannya bersifat reguler ada 2 record, bersifat taktis ada 1 record, dan yang bersifat darurat ada 1 record sehingga di dapat nilai Highnya sebagai berikut.

$$
\begin{aligned}
& \text { Entropy }(S)=\sum_{i=1}^{n}-p i \cdot \log _{2} p i \\
= & \left(-\frac{2}{4} \cdot \log _{2}\left(\frac{2}{4}\right)\right)+\left(-\frac{1}{4} \cdot \log _{2}\left(\frac{1}{4}\right)\right)+\left(-\frac{1}{4} \cdot \log _{2}\left(\frac{1}{4}\right)\right) \\
= & \left(-0.5 \cdot\left(\frac{-0.30103}{\log _{2}}\right)\right)+\left(-0.25 \cdot\left(\frac{-0.60205}{\log _{2}}\right)\right)+\left(-0.25 \cdot\left(\frac{-0.60205}{\log _{2}}\right)\right) \\
= & \left(-0.5 \cdot\left(\frac{-0.30103}{0.30103}\right)\right)+\left(-0.25 \cdot\left(\frac{-0.60205}{0.30103}\right)\right)+\left(-0.25 \cdot\left(\frac{-0.60205}{0.30103}\right)\right) \\
= & (-0.5 \cdot-1)+(-0.25 \cdot-1.9999)+(-0.25 \cdot-1.9999) \\
= & 0.5+0.4998+0.4998 \\
= & 1.9996
\end{aligned}
$$

5) Menghitung nilai gain untuk atribut limit peminjaman dengan nilai gain yang didapat sebagai berikut:

$$
\begin{aligned}
& \quad \operatorname{Gain}(S, A)=\operatorname{Entropy}(S)-\sum_{v \in \text { Values }(A)} \frac{\left|S_{v}\right|}{|S|} \operatorname{Entropy}\left(S_{v}\right) \\
& \operatorname{Gain}(S, A)=1.2537-\left(\frac{4}{10} \cdot(1.9996)+\frac{3}{10} \cdot(1.5846)+\frac{3}{10}(1.5846)\right) \\
& =1.2537-(0.7998+0.5282+0.5282) \\
& =1.2537-(1.8563) \\
& =-0.6025
\end{aligned}
$$

Perhitungan tersebut merupakan sample perhitungan, pada perhitungan Algortima C4.5 untuk mengambil nilai entropy dan nilai gain yang akan digunakan untuk pembuatan pohon keputusan dalam tahap 
selanjutnya, jumlah pinjaman adalah suatu kelas atau hasil klasifikasi yang ditentukan oleh peneliti dalam melakukan pengelompokan data dan akan dicari nilai entropy dan nilai gain sama seperti perhitungan dalam klasifikasi pada atribut limit pinjaman dan menghitung total record. Hasil yang didapat sebagaimana ditampilkan pada Tabel 3 untuk data yang didapat hasil dari perhitungan Algoritma C4.5.

Tabel.3. Hasil perhitungan algoritma C4.5

\begin{tabular}{|c|c|c|c|c|c|c|}
\hline Riwayat & $\begin{array}{c}\text { Jumlah } \\
\text { Data }\end{array}$ & $\begin{array}{c}\text { Pinjaman } \\
\text { Reguler }\end{array}$ & Pinjaman Taktis & Pinjaman Darurat & Entropy & Gain \\
\hline Total Record & 10 & 4 & 3 & 3 & 1.2537 & \\
\hline Limit Pinjaman & & & & & & -0.4969 \\
\hline Low & 3 & 1 & 1 & 1 & 1.5846 & \\
\hline Medium & 3 & 1 & 1 & 1 & 1.5846 & \\
\hline High & 4 & 2 & 1 & 1 & 1.9996 & \\
\hline $\begin{array}{l}\text { Jumlah } \\
\text { Pinjaman }\end{array}$ & & & & & & -0.3113 \\
\hline$\leq 450.000,-$ & 4 & 2 & 1 & 1 & 1.5846 & \\
\hline$>450.000,-$ & 6 & 2 & 2 & 2 & 1.5565 & \\
\hline & & & & & & 0.013 \\
\hline$\leq 900.000,-$ & 7 & 4 & 1 & 2 & 1.3788 & \\
\hline > 900.000,- & 3 & 0 & 2 & 1 & 0.9182 & \\
\hline & & & & & & -0.1224 \\
\hline$\leq 1.350 .000,-$ & 9 & 4 & 3 & 2 & 1.529 & \\
\hline$>1.350 .000,-$ & 1 & 0 & 0 & 1 & 0 & \\
\hline
\end{tabular}

Dari hasil pada Tabel 3 dapat diketahui bahwa nilai gain tertinggi terdapat pada data peminjaman uang Rp 900.000,- maka dapat digambarkan pohon keputusan berdasarkan hasil perhitungan algoritma C4.5 seperti pada Gambar 2.

Berdasarkan hasil dari pohon keputusan pada Gambar 2 dapat diketahui bahwa anggota koperasi yang meminjam uang dengan kisaran Rp 450.000,- termasuk dalam jenis peminjaman reguler, peminjaman taktis, dan peminjaman darurat. Anggota tersebut merupakan anggota tetap koperasi, dan status peminjamannya ada yang direkomendasikan dan tidak direkomendasikan untuk diberikan pinjaman. Sedangkan peminjam uang dengan kisaran Rp 900.000,- juga termasuk jenis peminjaman reguler, peminjaman taktis, dan peminjaman darurat yang berasal dari anggota tetap koperasi dan direkomendasikan untuk diberi pinjaman. Selain itu, ada anggota koperasi yang meminjam uang dengan kisaran Rp 1.350.000,- yang masuk dalam jenis peminjaman darurat dari anggota tetap dengan hasil tidak direkomendasikan.

Adapun cara menerjemahkan hasil dari pohon keputusan pada Gambar 2 adalah sebagai berikut.

1) Jika anggota melakukan pinjaman $450.000,-=$ anggota tetap. Jika anggota direkomendasikan dengan peminjaman 450.000,- = anggota tetap, maka anggota mendapatkan layanan pinjman darurat. 
2) Jika anggota melakukan pinjaman $450.000,-=$ anggota tetap. Jika anggota direkomendasikan dengan peminjaman $450.000,-=$ anggota tetap, maka akan diberikan hak pinjaman taktis.

3) Jika anggota melakukan pinjaman 450.000,- = anggota tetap. Jika anggota tidak direkomendasikan dengan peminjaman $450.000,-=$ anggota tetap, maka tidak akan diberikan hak pinjaman reguler.

4) Jika anggota melakukan pinjaman $900.000,-=$ anggota tetap. Jika anggota direkomendasikan dengan peminjaman $900.000,-=$ anggota tetap, maka akan mendapat layanan pinjaman reguler.

5) Jika anggota melakukan pinjaman $900.000,-=$ anggota tetap. Jika anggota direkomendasikan dengan peminjaman $900.000,-=$ anggota tetap, maka akan mendapat layanan pinjaman taktis.

6) Jika anggota melakukan pinjaman $900.000,-=$ anggota tetap. Jika anggota direkomendasikan dengan peminjaman $900.000,-=$ anggota tetap, maka akan mendapat layanan pinjaman darurat.

7) Jika anggota melakukan pinjaman $1.350 .000,-=$ anggota tetap. Jika anggota tidak direkomendasikan dengan peminjaman $1.350 .000,-=$ anggota tetap, maka tidak berhak mendapat layanan pinjaman darurat.

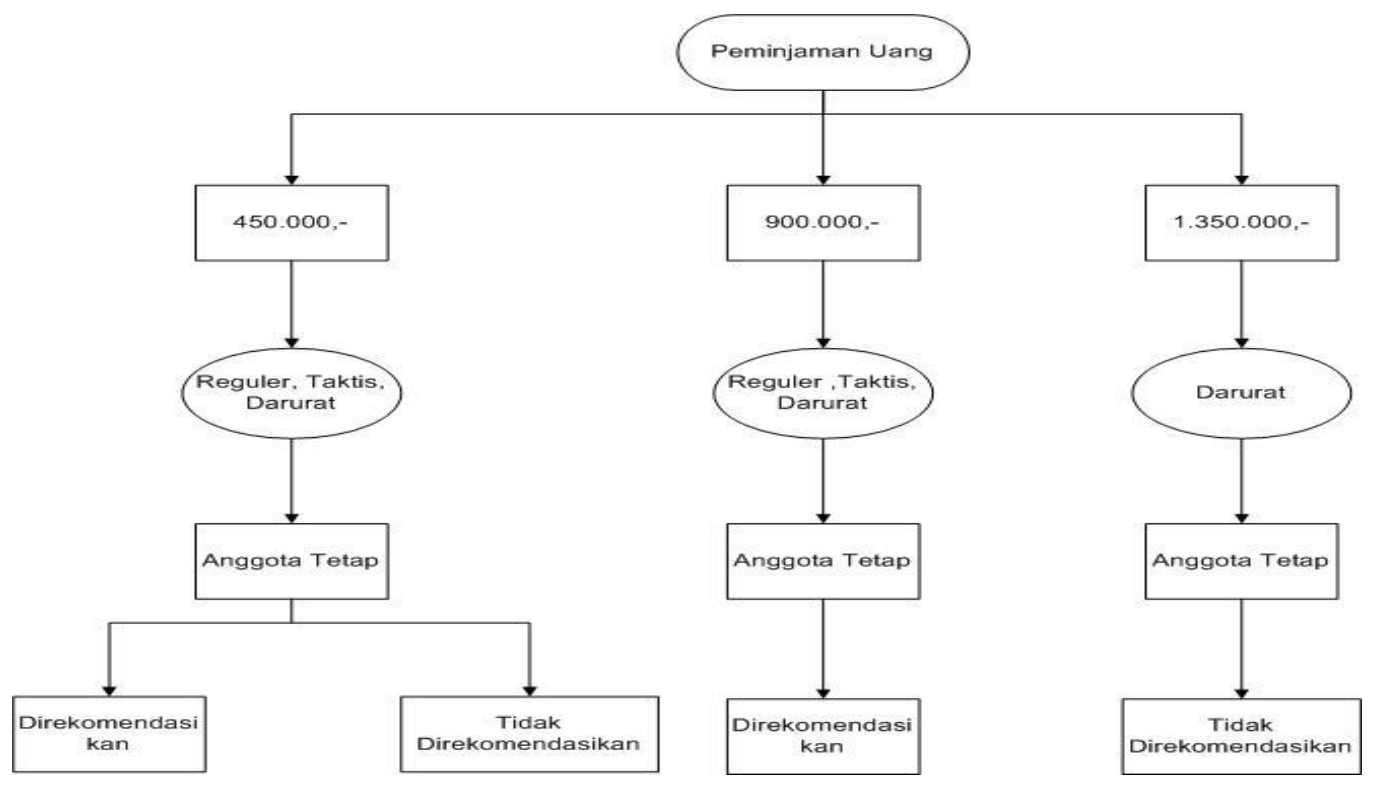

Gambar 2. Pohon keputusan hasil perhitungan C4.5

Tabel.4. Dataset peminjaman uang

\begin{tabular}{llllll}
\hline No & Nama Anggota & Limit Pinjaman & Jumlah Pinjaman & Jenis Pinjaman & Status Pinjaman \\
\hline 1 & Andi & High & Rp. 685.000,- & Reguler & Rekomendasi \\
2 & Rian & Medium & Rp. 1.000.000,- & Taktis & Rekomendasi \\
3 & Putri & Medium & Rp. 490.000,- & Darurat & Rekomendasi \\
4 & Rina & Low & Rp. 354.500,- & Reguler & Rekomendasi \\
5 & Budi & High & Rp. 172.500,- & Taktis & Rekomendasi \\
6 & Dani & Low & Rp. 558.000,- & Reguler & Rekomendasi \\
7 & Andika & Medium & Rp. 1.389.000,- & Darurat & Tidak Rekomendasi \\
8 & Sinta & Rp. $981.000,-$ & Taktis & Rekomendasi \\
9 & Randy & High & Rp. 467.300,- & Reguler & Rekomendasi \\
10 & Bani & Low & Rp. 201.100,- & Darurat & Tidak Rekomendasi \\
\hline
\end{tabular}


Tabel 4 memberikan kesimpulan tentang hasil rekomendasi peminjaman, bahwa ada 8 anggota yang direkomendasikan untuk diberikan peminjaman, dan 2 anggota sisanya tidak direkomendasikan untuk diberikan peminjaman dikarenakan Limit Peminjaman tidak memenuhi persyaratan untuk melakukan peminjaman. Hal ini dikarenakan untuk keamanan transaksi dan data pada keberlangsungan koperasi [20].

Adapun kekurangan dari algoritma $\mathrm{C} 4.5$ yaitu terjadinya overlap pada hasil keputusan dan kriteria pengambilan keputusan yang sangat banyak mengakibatkan bertambahnya waktu dari hasil prediksi sebelumnya [17].

\section{Kesimpulan}

Adapun hasil kesimpulan dan saran dari penelitian ini antara lain sebagai berikut.

\subsection{Simpulan}

Simpulan yang didapat dari Dataset peminjaman adalah dari jumlah permohonan peminjaman sebanyak 10 record hanya 8 yang direkomendasikan untuk diberikan pinjaman. Hal ini dikarenakan Limit Peminjaman tidak memenuhi syarat peminjaman. Dengan adanya penerapan Algoritma C4.5 diharapkan dapat membuat keuangan kas Koperasi Sejahtera Mandiri koperasi tetap kondusif, dan kemudian dijelaskan dalam bentuk pohon keputusan dengan menggunakan metode algoritma C4.5 (Decission Tree). Dengan metode ini dapat dilihat bahwa dari data Limit Peminjaman dan Jenis Peminjaman bisa megendalikan keuangan dan mengelompokan peminjaman. Adapun tujuan lain yang dapat dicapai melalui hasil rekomendasi ini adalah untuk mengelola keuangan Koperasi Sejahtera Mandiri dengan baik dan menghindari kerugian karena peminjaman yang tak terkendali.

\subsection{Saran}

Adapun saran untuk masalah peminjaman uang yaitu penulis mengharapkan dapat melanjutkan ke tahap pembuatan sistem informasi untuk memudahkan dalam transaksi peminjaman uang. Sistem informasi ini diharapkan dapat lebih meminimalisir risiko adanya keputusan yang kurang tepat (overlap) dan tidak efektifnya waktu pada hasil prediksi.

\section{Daftar Rujukan}

[1] E. Elisa, “Analisa dan Penerapan Algoritma C4.5 Dalam Data Mining Untuk Mengidentifikasi Faktor-Faktor Penyebab Kecelakaan Kerja Kontruksi PT. Arupadhatu Adisesanti," vol. 2, no. 1, pp. 36-41, 2017.

[2] P. Meilina, "Penerapan Data Mining Dengan Metode Klasifikasi Menggunakan Decision Tree dan Regresi," J. Teknol., vol. 7, no. 1, pp. 11-20, 2015.

[3] F. Masya, E. Elvina, and R. Caturandy, "E-Voucher Taksi Menentukan Jarak Terpendek Dengan Algoritma Djikstra Studi Kasus: Pt Mii,” J. Ilm. FIFO, vol. 7, no. 1, p. 106, 2017.

[4] H. Mustafidah, "Model Regresi Data Mining Motivasi Belajar Pengaruhnya Terhadap Tingkat Kedisiplinan Mahasiswa," JOIN, vol. I, pp. 1-4, 2017.

[5] D. L. Fithri, "Model Data Mining Dalam Penentuan Kelayakan Pemilihan Tempat Tinggal Menggunakan Metode Naive Bayes," Simetris J. Tek. Mesin, Elektro dan Ilmu Komputer., vol. 7, no. 2, p. 725, 2016.

[6] H. Sulastri and A. I. Gufroni, "Penerapan Data Mining Dalam Pengelompokan Penderita Thalasaemia," J. Nas. Teknol. dan Sist. Inf., vol. 02, pp. 299-305, 2017.

[7] I. Surya, "Kebutuhan Perangkat Lunak Untuk Aplikasi Data Mining," J. Nas. Teknol. dan Sist. InformasiSistem Inf., vol. 02, pp. 233-240, 2017.

[8] L. Zahrotun, T. Setiadi, and T. Mufti, “Aplikasi Data Mining untuk Mencari Pola Asosiasi Tracer Study Menggunakan Algoritma FOLDARM,” J. Nas. Teknol. dan Sist. Inf., vol. 01, pp. 37-43, 2018.

[9] A. Saifudin, "Metode Data Mining Untuk Seleksi Calon Mahasiswa” J. Teknol., vol. 10, no. 1, pp. 25-36, 2018.

[10] Yasmiati, Wahyudi, and A. Susilo, "Pengembangan Aplikasi Data Mining Dengan Algoritma C4.5 Dan Apriori di Fakultas Teknologi Informatika Universitas Respati Indonesia," J. Teknol., vol. 9, no. 1, 2017.

[11]A. S. B. Asmoro, W. S. G. Irianto, and U. Pujianto, "Perbandingan Kinerja Hasil Seleksi Fitur pada Prediksi Kinerja Akademik Siswa Berbasis Pohon Keputusan,” J. Edukasi dan Penelit. Inform., vol. 4, no. 2, p. 84, 2019. 
[12] S. Aswati, Ada Udi Firmansyah, William Ramdhan, “Analisis dan Perancangan Sistem Informasi Data Siswa Pada Sekolah Menengah Kejuruan (SMK) PGRI 8 Medan dengan Zachman Framework” J. SISFO, vol. 06, no. 03, 2017.

[13]L. Muflikhah, W. L. Yunita, and M. T. Furqon, "Prediksi Nilai Mata Kuliah Mahasiswa Menggunakan Algoritma K-Apriori,” J. SISFO, vol. 06, no. 02, pp. 157-172, 2017.

[14]D. H. Kamagi, H. Seng. Implementasi Data Mining dengan Algoritma C4.5 untuk Memprediksi Tingkat Kelulusan Mahasiswa. ULTIMATICS, ISSN 2085-4552, Vol 6, No 1, 2014.

[15] S. L. Br Ginting, W. Zarman, I. Hamidah "Analisis dan Penerapan Algoritma C4.5 dalam Data Mining untuk Memprediksi Masa Studi Mahasiswa Berdasarkan Data Nilai Akademik,” Snast, vol. 3, no. 1, pp. 211-216, 2014.

[16] A. Rohman, V. Suhartono, \& C. Supriyanto. Penerapan algoritma c4.5 berbasis ADABOOST untuk Prediksi Penyakit Jantung. Vol 13, No 1, pp 13-19, 2017.

[17]F. F. Harryanto \& S. Hansun. Penerapan Algoritma C4.5 untuk Memprediksi Penerimaan Calon Pegawai Baru di PT WISE. Jurnal Teknik Informatika Dan Sistem Informasi, Vol 3, No 2, pp 95-103, 2017.

[18] H. Widayu, S. Darma, N. Silalahi, \& Mesran. Data Mining Untuk Memprediksi Jenis Transaksi Nasabah Pada Koperasi Simpan Pinjam Dengan Algoritma C4.5. Media Informatika Budidarma. Issn 2548-8368, Vol 1, No 7, 2017.

[19] I. Rahmayuni. Perbandingan performansi algoritma c4.5 dan cart dalam klasifiksi data nilai mahasiswa prodi teknik komputer politeknik negeri padang. Teknoif, Vol 2, No 1, pp 40-46. https://doi.org/10.1016/j.jnc.2008.09.001, 2014.

[20]B. V. Indriyono, “Integrasi Algoritma Kriptografi Blowfish dengan Steganografi LSB untuk Pengamanan Data pada File MP3,” J. SISFO, vol. 08, no. 03, 2019. 
Muhammad Imam Tegar dan Wachyu Hari Haji / Jurnal SISFO Vol.09 No.01 (2019) 15-28

Halaman ini sengaja dikosongkan 
